\title{
Smart Hospitals Need Smart Managers
}

\author{
Mohammadkarim Bahadori', Khalil Alimohammadzadeh ${ }^{2,3^{*}}$, Ramin Ravangard $^{4}$ \\ ${ }^{1}$ Health Management Research Center, Baqiyatallah University of Medical Sciences, Tehran, Iran \\ ${ }^{2}$ Department of Healthcare Management, School of Management and Social Sciences, North Tehran Branch, Islamic \\ Azad University, Tehran, Iran \\ ${ }^{3}$ Health Economics Policy Research Center, Tehran Medical Sciences Islamic Azad University, Tehran, Iran \\ ${ }^{4}$ Health Human Resources Research Center, School of Management \& Information Sciences, Shiraz University of \\ Medical Sciences, Shiraz, Iran
}

*Corresponding Author: Khalil Alimohammadzadeh, M.D., Ph.D. in Health Services Management, Associate Professor, Department of Healthcare Management, School of Management and Social Sciences, North Tehran Branch, Islamic Azad University, Tehran, Iran. Tel: +98-2122977862, Email: dr_khalil_amz@yahoo.com

Received October 1, 2019; Accepted November 11, 2019; Online Published December 3, 2019

\section{Dear Editor,}

Today, hospitals that rely solely on computerized information systems cannot respond to the growing healthcare needs around them. Therefore, the use of electronic health systems is absolutely essential, and smart hospitals, meanwhile, have a special place. Considering and dealing with such hospitals brings us into a new and complex world. One of the challenges of these systems is how to create interaction between different people and tools, especially in data exchange, at different levels. Smart hospitals need to quickly discern the health events occurring around them and be able to respond to them effectively through the use of appropriate architecture, standard technologies, efficient software, and integrated management. This requires the development of an advanced, responsive, and secure environment in which the legal frameworks, ethics, and legal standards are respected. The effort to build smart hospitals in all developed and developing countries has now become a major concern. Iran is also embarking on this new path. The gateway to this path is the creation of a system that completely collects, stores, and analyzes the patients' information and medical records. Some countries have also incorporated the administrative, financial, and economic activities of medical institutions into this automation, thereby improving and accelerating many processes. It can be said that this is a major characteristic of information technology that extends the depth, speed, and evolution of all sectors and creates synergy. ${ }^{1,2}$

Smart hospital management requires smart managers. Some characteristics of such managers are promoting teamwork, paying attention to the emotional or psychological characteristics of team members, creating an appropriate organizational culture, committing to common goals, understanding competitive market conditions, having the ability to create economies of scale, providing crisis management, resolving internal organizational conflicts and tensions, having the ability to anticipate problems and provide alternative solutions, and being able to think strategically.

Strategic thinking enables smart managers to have a systematic approach to various issues, act in a systematic way, strengthen the power of creative hypotheses within themselves and the organization, think constantly over time, and always focus on the appropriate goal and direction. Four strategic thinking commands for smart managers include continuous learning from the environment and moving to full intelligent environment, discovering the unmet needs of internal and external stakeholders of the organization, creating innovative and value-creating solutions, and establishing dynamic, coherent, and controlled management. ${ }^{1,2}$

Managers of smart organizations should often act as benevolent supporters. Smart organizations should, at the same time, be advanced cultural organizations so that taking into account human communication, people become involved in the work, complement each other's skills, and take advantage of any creativity and innovation.

We work with smart people and tools in smart hospitals that are productive, patient-centered, and customer-centric, and this requires us to acquire the necessary training, skills, and abilities to establish total quality management. Smart hospitals don't just need smart tools; they also need smart people and managers in different dimensions. ${ }^{3}$

\section{Authors' Contributions}

All authors contributed equally to this study. 


\section{Conflict of Interest Disclosures}

The authors declare that they have no conflicts of interest.

\section{Ethical Approval}

Not applicable.

\section{References}

1. Liedtka JM. Strategic thinking: can it be taught? Long
Range Plann. 1998;31(1):120-129. doi:10.1016/S00246301(97)00098-8.

2. Moro Visconti R, Martiniello L. Smart hospitals and patientcentered governance. Corp Ownersh Control. 2019;16(2):8396. doi:10.22495/cocv16i2art9.

3. Mayo AT, Woolley AW. Teamwork in health care: maximizing collective intelligence via inclusive collaboration and open communication. AMA J Ethics. 2016;18(9):933-940. doi:10.1001/journalofethics.2016.18.9.stas2-1609. 